\title{
New Born Children with NTD
}

\author{
Dr. Shilpa. Karkera ${ }^{1 *}$ \\ ${ }^{1}$ Assistant Professor, Dept. of Neuroscience \& Anatomy, Trinity School of Medicine St. Vincent \& the Grenadines
}

DOI: $10.36348 /$ sijap.2022.v05i01.002 $\quad$ | Received: 11.12.2021 | Accepted: 17.01 .2022 | Published: 19.01 .2022

*Corresponding author: Dr. Shilpa. Karkera

Assistant Professor, Dept. of Neuroscience \& Anatomy, Trinity School of Medicine St. Vincent \& the Grenadines

\section{Abstract}

Background: The aim of the study was to describe epidemiological aspects and clinical characteristics of these patients, as well as diagnostic work-up, comprehensive management and updated follow-up. Methods: In a 4-years' period, 6 female and 4 male fetuses were diagnosed with NTD in Department of OBG at Victoria Hospital, BMCRI, Bangalore. Analyzed data were related to familiar and/or maternal risk factors (consanguinity, maternal preexisting and/or gestational diseases, exposure to teratogen/infectious agents, lack of preconception folic acid supplement), demographic (ethnicity/origin, residence) and clinical features (eventual use of assisted reproduction techniques, prenatal diagnosis, gestational age, fetal presentation, type of delivery, birth weight, preoperative imaging, antibiotics and analgesics use, description of the surgery intervention, length of hospital stay, comorbidities, complications), and follow-up. Results: Among 10 cases, 6 female and 4 male fetuses were diagnosed with NTD. All 10 fetuses had Anencephaly and other associated anomalies. The diagnosis was made by prenatal ultrasonography. Among ten mothers one was over-aged. Medical history revealed that only 2 mothers used folic acid (FA), -tablets containing $5 \mathrm{mg}$ folic acid, once daily, beginning after being aware of the pregnancy- neither initiated preconceptionally, nor consumed regularly. The remaining 8 mothers did not use any supplements. No mothers used any kind of drugs during pregnancy, and 2 were diabetic. All patients had normal thyroid, liver and renal function tests. Abdominal ultrasonography revealed no abnormality.

Keywords: Consanguinity, Maternal age, socioeconomic status, Fortification, Spina bifida cystica.

Copyright () 2022 The Author(s): This is an open-access article distributed under the terms of the Creative Commons Attribution 4.0 International License (CC BY-NC 4.0) which permits unrestricted use, distribution, and reproduction in any medium for non-commercial use provided the original author and source are credited.

\section{INTRODUCTION}

Neural tube defects (NTDs) are congenital malformations of the central nervous system [1]. They are caused by partial/incomplete closure of the neural tube during development, between 21 and 28 days after conception. These types of birth defects develop very early during pregnancy, often before a woman knows she is pregnant.

The two most common NTDs are spina bifida (a spinal cord defect) and anencephaly (a brain defect).In spina bifida, the fetal spinal column doesn't close completely. Spina bifida is further divided into two subclasses, spina bifida cystica and spina bifida occulta. Spina bifida cystica includes meningocele and myelomeningocele. Spina bifida occulta means hidden split spine [1].

In anencephaly, most of the brain and skull do not develop which results in little to no brain, encephalocele which affects the skull. Encephaloceles are characterized by protrusions of the brain through the skull that are sac-like and covered with membrane. They can be a groove down the middle of the upper part of the skull, between the forehead and nose, or the back of the skull. Due to the range in its location, encephaloceles are classified by the location as well as the type of defect it causes. Subtypes include occipital encephalocele, encephalocele of the carnival vault, and nasal encephaloceles (frontoethmoidal encephaloceles and basal encephaloceles), with approximately $80 \%$ of all encephaloceles occurring in the occipital area. Encephaloceles are often obvious and diagnosed immediately. Sometimes small encephaloceles in the nasal and forehead are undetected. Inspite of wide range in its implications, encephaloceles are most likely to be caused by improper separation of the surface ectoderm and the neuroectoderm after the closure of the neural folds in the fourth week of gastrulation [2, 3]. Foetuses with anencephaly are usually either stillborn or die shortly after birth. 
Karkera Shilpa; Sch Int J Anat Physiol, Jan., 2022; 5(1): 9-14

The Neural tube defects resulted in 71,000 deaths globally in 2010 [4]. Neural tube defects (NTDs) are among the leading noninfectious birth defects with a worldwide prevalence of 1-2 per 1000 live births [5].

The prevalence of NTDs in India has been reported to vary from 0.5 to 11 per 1000 births [6-8]. There are many maternal factors that also play a role in prevalence rates of NTDs. These factors includes maternal age, obesity and socioeconomic status along with many others. Maternal age hasn't been shown to have a huge impact on prevalence rates, but when there has been a relationship identified, older mothers along with very young mothers are at an increased risk. While maternal age may not have a huge impact, mothers that have a body mass index greater than 29 double the risk of their child having an NTD. Studies have also shown that mothers with three or more previous children show moderate risk for their next child having an NTD [9].

If you have already had an NTD-affected pregnancy, CDC recommends consuming $400 \mathrm{mcg}$ of folic acid each day, even if you are not planning to become pregnant. When planning to become pregnant, CDC recommends consuming $4,000 \mathrm{mcg}$ of folic acid each day starting 1 month before becoming pregnant and during the first 3 months of pregnancy. This recommendation to take a higher dose of folic acid is based on data from the most rigorous type of scientific study involving women with a previous NTD-affected pregnancy. Dosages lower than 4,000 mcg of folic acid have not been studied in women who have had a previous NTD-affected pregnancy.

In present study we describe 10 cases with NTDs, their clinical findings, surgical intervention and follow-up. The aim of the study was to describe epidemiological aspects and clinical characteristics of these patients, as well as diagnostic work-up, comprehensive management and updated follow-up.

\section{MATERIAL \& METHODS}

Between August 2014 and October 2017 aborted fetuses that were diagnosed with NTDs were collected from OBG department, Victoria Hospital, BMCRI, Bangalore. Gestational week, gestation history, folic acid administration during early pregnancy, physical findings, medical and surgical treatment history as well as postoperative problems and follow-up consequences were evaluated. All patients and families were called for a thorough evaluation of physical findings and neurological examination. Written Consent was taken from all the families.

\section{RESULTS}

In a 4-years' period, 6 female and 4 male fetuses were diagnosed with NTD (Table 1). All 10 fetuses had Anencephaly and other anomalies. The diagnosis was made by prenatal ultrasonography. Among ten mothers one (Case 2) was over-aged (45years old). Medical history revealed that only 2 mothers used folic acid (FA), -tablets containing $5 \mathrm{mg}$ folic acid, once daily, beginning after being aware of the pregnancy- neither initiated preconceptionally, nor consumed regularly. The remaining 8 mothers did not use any supplements. No mothers used any kind of drugs during pregnancy, and 2 were diabetic. All the families were natives of the city, and no close consanguinity was revealed. None of the families had another child with any kind of congenital anomalies, including cranial defects. Mother of Case 2 was exposed to radiation as she was not aware of her pregnancy at 5 months of gestation. None of the babies were products of IVF. All babies were born with cesarean section. Case 1 to Case 10 had Anencephaly (Figure 1).Case 3 had Anencephaly with dismorphic face and contractures at elbows. Case 4 additionally had encephalocele along with craniorachischisis(Figure 2). Pre- and postoperative weight, height and head circumference and relevant demographic data are given in Table 1. All patients had normal thyroid, liver and renal function tests. Abdominal ultrasonography revealed no abnormality in any child. Case 5 was operated on the second day of her life and was lost due to respiratory failure after operation.

The karyotype analysis of Case 3 was tested positive for down's syndrome (Figure 3).

Table-1: The demographic data, Epidemiological data \& physical findings of the fetuses with NTD

\begin{tabular}{|c|c|c|c|c|c|c|c|c|c|c|}
\hline & Case1 & Case 2 & Case 3 & Case 4 & Case 5 & Case 6 & Case 7 & Case 8 & Case 9 & Case 10 \\
\hline $\begin{array}{l}\text { Gestational } \\
\text { week }\end{array}$ & 22 & 20 & 26 & 30 & 22 & 30 & 28 & 25 & 22 & 20 \\
\hline $\begin{array}{l}\text { Prenatal } \\
\text { Diagnosis }\end{array}$ & Yes & Yes & Yes & Yes & Yes & Yes & Yes & Yes & Yes & Yes \\
\hline Maternal age & 26 & 28 & 45 & 50 & 18 & 23 & 26 & 25 & 21 & 30 \\
\hline Paternal age & 30 & 32 & 50 & 52 & 30 & 31 & 39 & 28 & 29 & 35 \\
\hline Consanguinity & No & No & No & Yes & $\mathrm{No}$ & No & No & No & No & No \\
\hline $\begin{array}{l}\text { No of } \\
\text { Pregnancy }\end{array}$ & 3 & 2 & 1 & 2 & 5 & 3 & 4 & 2 & 2 & 1 \\
\hline $\begin{array}{l}\text { FA } \\
\text { consumption }\end{array}$ & Irregular & None & None & None & None & None & None & None & None & Irregular \\
\hline Sex & Female & Male & Female & Female & Female & Female & Female & Male & Male & Male \\
\hline Birth & $1259 \mathrm{gr}$ & $1123 \mathrm{gr}$ & $1860 \mathrm{gr}$ & $2200 \mathrm{gr}$ & $1198 \mathrm{gr}$ & $2300 \mathrm{gr}$ & $2403 \mathrm{gr}$ & $1690 \mathrm{gr}$ & $1324 \mathrm{gr}$ & $1280 \mathrm{gr}$ \\
\hline
\end{tabular}


Karkera Shilpa; Sch Int J Anat Physiol, Jan., 2022; 5(1): 9-14

\begin{tabular}{|c|c|c|c|c|c|c|c|c|c|c|}
\hline & Case1 & Case 2 & Case 3 & Case 4 & Case 5 & Case 6 & Case 7 & Case 8 & Case 9 & Case 10 \\
\hline weight(grams) & & & & & & & & & & \\
\hline $\begin{array}{l}\text { Birth CR } \\
\text { length }(\mathrm{mm})\end{array}$ & 181 & 178 & 209 & 230 & 178 & 259 & 248 & 221 & 159 & 200 \\
\hline $\begin{array}{l}\text { Other } \\
\text { anomaly }\end{array}$ & None & None & $\begin{array}{l}\text { Dimorphic } \\
\text { face and } \\
\text { narrow } \\
\text { chest }\end{array}$ & Craniorachischisis & None & None & None & None & None & None \\
\hline Convulsion & No & No & No & Yes & No & Yes & No & No & No & No \\
\hline $\begin{array}{l}\text { Chromosome } \\
\text { Analysis }\end{array}$ & N/D & N/D & Performed & N/D & N/D & N/D & N/D & N/D & N/D & N/D \\
\hline
\end{tabular}

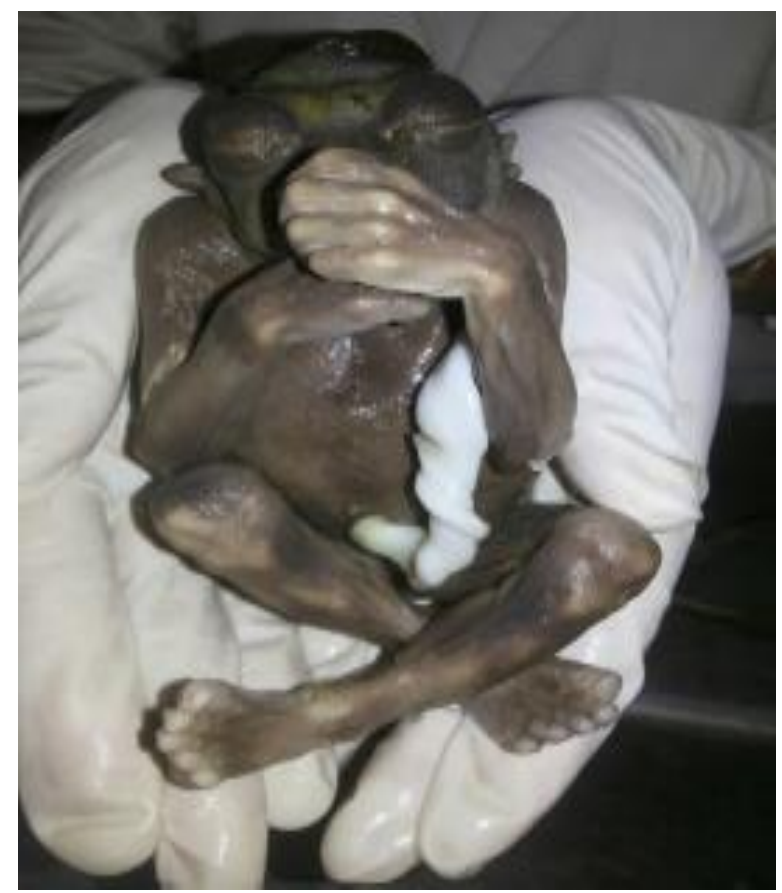

Fig-1: Anencephalic fetus

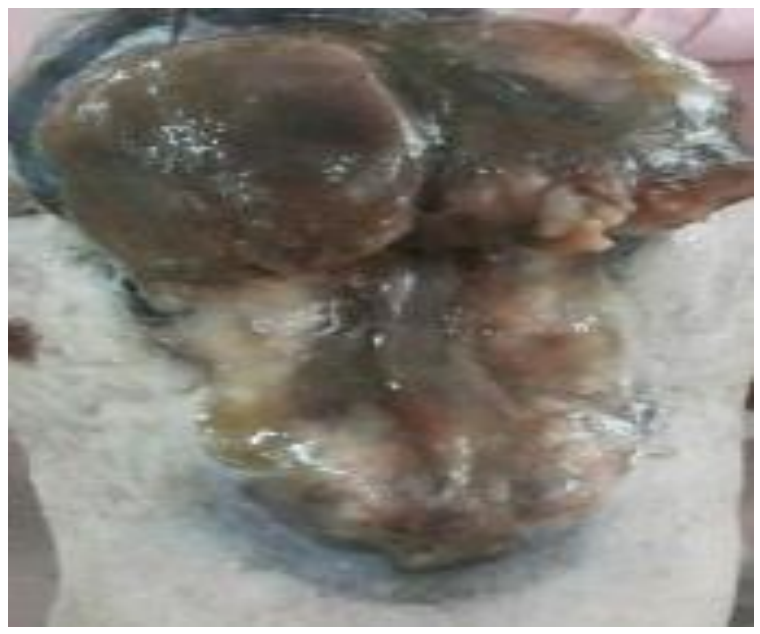

Fig-2: Anencephaly with encephalocele and Craniorachischisis

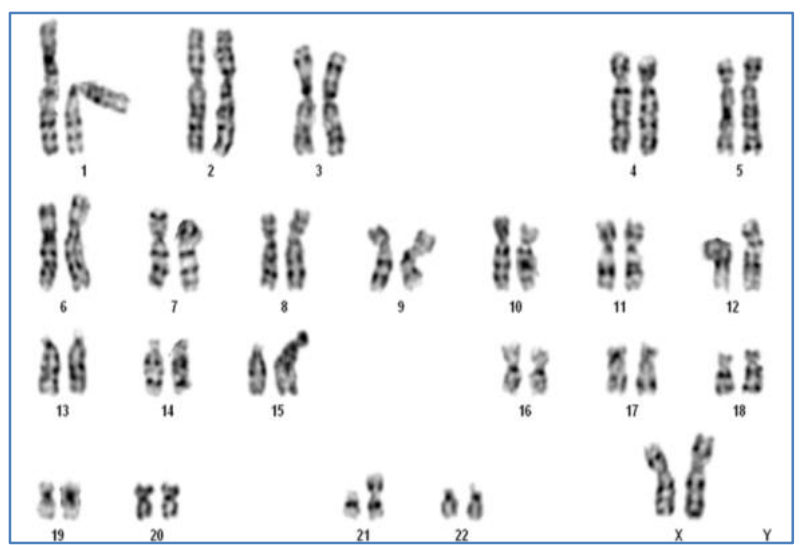

Fig-3: Case 3 had 46, XX, der $(21 ; 21)(q 10 ; q 10),+21$

(Down's syndrome - translocation type).

\section{DISCUSSION}

The term "spina bifida" was first named in 1641 by Nicholas Tulp [10]. The spread of surgical treatment of open NTDs and the knowledge of pathophysiology along with epidemiology and genetics of such defects were reached much later, in the late 20th century [11].

In 1998, mandatory fortification of enriched cereal grain products were initiated, whose adoption resulted in a $28 \%$ reduction in NTDs prevalence (from 10.7 cases/1000 in 1992 to 7/1000 in 1998) [9]. Indeed, after the initial reduction, birth prevalence remained stable since 1999 , with nearly a quarter $(21.6 \%)$ of childbearing age women who still have low red blood folate concentration associated with a higher risk for NTDs. Moreover, fortification mandates are still not universally embraced, and most countries are not fortifying grains or rice with folate [10].

Neural tube defects (NTDs) are congenital structural abnormalities of the central nervous system and vertebral column. Neural tube defects may occur as an isolated malformation, in combination with other malformations, as part of a genetic syndrome, or as a result of teratogenic exposure. Neural tube defects are the second-most-common major congenital anomalies after cardiac malformations, and their prevalence varies by geographic region, race, and environmental factors [11]. 
Most NTDs are uncommon and multifactorial: an oligogenic/polygenic inheritance (genes regulating folate and methionine metabolism, and others involved in planar cell polarity signaling pathway) interrelated with influencing environmental factors [12-14]. Risk factors include: maternal folate deficiency, diabetes, obesity, exposure to teratogens (valproic acid and carbamazepine, lead and tetrachloroethylenecontaminated drinking water, arsenic, pesticides, mycotoxins, fungus contaminants of maize, heat and influenza virus), specific parental occupations and low socioeconomic status [15]. Recurrence risk of a second affected child is increased by 3-5 folds for couples with one sick infant, compared to the general population. A significant proportion (10\%) of NTDs are associated with syndromes and/or chromosomal anomalies/congenital malformations, and the correlation is more marked (20\%) in some ethnic groups (i.e. Arab populations with increased prevalence of autosomal recessive diseases, reflecting their high coefficient of consanguinity) [16]. Associated conditions included are: VACTERL association (vertebral abnormalities, anal atresia, cardiac defects, tracheal anomalies including tracheo-esophageal fistula, esophageal atresia, renal anomalies, limb anomalies, MIM:192350), amniotic band sequence, Currarino syndrome (a peculiar form of caudal regression syndrome, also known as autosomal dominant sacral agenesis, MIM:176450), Waardenburg syndrome, Joubert syndrome, Meckel-Gruber syndrome and some chromosomal abnormalities like trisomy 13 , trisomy 18 , triploidy and partial aneuploidy [17]. Many studies provided evidence that folate fortification reduces the incidence of anencephaly [18-20].

A case control study conducted by Tadasee et al on neural tube defects in 400 newborns (133cases and 267 controls), fifty percent $(48 \%)$ of the cases were contributed by anencephaly. After controlling the covariates, living in rural areas $(\mathrm{AOR}=1: 78: 95 \% \mathrm{CI}$ 1.02,3.11), being illiterate $(\mathrm{AOR}=1: 81: 95 \%$ CI 1.07, 4.61), being female newborn (AOR $=1: 95$ : $95 \%$ CI 1.09, 3.50), having no ANC follow-up (AOR = 1:93: $95 \%$ CI 1.17, 5.04), and having a previous history of NTDs $(A O R=4: 39: 95 \%$ CI 2.42, 7.96) were the risk factors for NTDs., being supplemented with folic acid or multivitamins before or during pregnancy (AOR = 0:37: 95\% CI 0.21, 0.65), never having taken any substance during pregnancy $(\mathrm{AOR}=0: 42: 95 \% \mathrm{CI}$ $0.21,0.88)$, and being free from medical illnesses during pregnancy $(\mathrm{AOR}=0: 27: 95 \%$ CI $0.11,0.69)$ were the protective factors of NTDs [21].

The retrospective analytical study was carried out by analyzing the medical case records of women who delivered babies with neural tube defects between January 2005 to December 2008 in Haryana. Sixty seven babies had neural tube defects thus accounting for a NTD prevalence of 2.62/1000 births. Among these, 48 cases of anencephaly, 15 cases of meningocele and/or meningomyelocele, 4 cases of spina bifida occulta. Anencephaly was most prevalent in primiparous women of low literacy aged between 21-25 years. Similar trends were visible in meningomyelocele and spina bifida groups. Most women in the study were homemakers with almost equitable distribution in rural and urban areas. No preponderance of any particular blood group was evident for any of the neural tube defects [22].

The study conducted on birth-outcomes surveillance at hospitals throughout Botswana, in 20142019. In 119,477 deliveries; $119,033(99.6 \%)$ had an infant surface examination that could be evaluated, and 98 neural-tube defects were identified $(0.08 \%$ of deliveries). Among 1683 deliveries in which the mother was taking dolutegravir at conception, 5 neural-tube defects were found $(0.30 \%$ of deliveries $)$; the defects included two instances of myelomeningocele, one of anencephaly, one of encephalocele, and one of iniencephaly. The 15 neural-tube defects were found among 14,792 deliveries $(0.10 \%)$ in which the mother was taking any non-dolutegravir ART at conception, 3 among $7959(0.04 \%)$ in which the mother was taking efavirenz at conception, 1 among $3840(0.03 \%)$ in which the mother started dolutegravir treatment during pregnancy, and 70 among $89,372(0.08 \%)$ in HIVuninfected mothers. The prevalence of neural-tube defects was higher in association with dolutegravir treatment at conception than with non-dolutegravir ART at conception (difference, 0.20 percentage points; $95 \%$ confidence interval [CI], 0.01 to 0.59 ) or with other types of ART exposure. Major external structural defects were found in $0.95 \%$ of deliveries among women exposed to dolutegravir at conception and $0.68 \%$ of those among women exposed to nondolutegravir ART at conception (difference, 0.27 percentage points; $95 \% \mathrm{CI},-0.13$ to 0.87 ) [23].

Newborns and children with NTDs need a multidisciplinary approach and follow-up, involving neonatologists, neonatal surgeons, pediatric neurologists, urologists and orthopedician, geneticists, physiatrists, physiotherapists and neurorehabilitation therapists. The multidisciplinary team aims to guarantee to children and families, an individualized care oriented to maintain normal biologic functions and social life by preserving urinary and stool continence, lowering the possible infective risk, and planning and a neurodevelopmental follow-up.

In present study all 10 cases had Anencephaly and 2 cases had encephalocele along with anencephaly. All babies were born with cesarean section. One case had Anencephaly along with dismorphic face and contracture at elbows which was detected by karyotyping has Down's syndrome. One case had encephalocele along with craniorachischisis. All 
patients had normal thyroid, liver and renal function tests.

\section{CONCLUSIONS}

The benefits of preconception folic acid supplement awareness should be mandatory [19]. This is consistent with the data of our report, which showed a low rate/absence of folate supplement among the mothers of our patients. Adequate medical counseling may not reach women with unplanned pregnancies, and/or more vulnerable owing to socio-economic status. Since prenatal US screening cannot completely contain the impact on health systems that these defects exert in relation to the burden of complex care and morbidity/disability risks. These primary intervention remains our most important and effective tool. Thus, alternative preventive strategies should be considered. The patients with Prehistory of NTDs should perform Alphafeto protein test has the mandatory test during conception. They should also counseled to consume fortified foods and, through public health department to allow a free availability of preconception folic acid supplements to all women of childbearing age.

All health care departments like Gynecologists, Neonatologists and pediatricians should play important role with the goal of preventive and curative care pertaining to disability. We as a health care professional should try to reduce the NTDs by educating the untrained mothers about importance for Folic acid and Consanguineous marriage.

Every child has the right to be protected against any disease, even more if complex and burdened by high morbidity and mortality. This is particularly true for newborns with NTDs, for whom we have an extraordinary potential of prevention available. If this is not achieved, an early, multidisciplinary, individualized and family centered as well as longitudinal management should be guaranteed.

\section{Acknowledgements \\ Not applicable.}

\section{Funding}

No funding was granted for this research.

\section{Ethics approval and consent to participate}

Written informed consent was obtained from both parents at birth or admission of their newborns. The study was approved by the BMCRI; ethical committee. All procedures performed in this study were in accordance with the ethical standards of the institutional and national research committee, and with the 1964 Helsinki declaration and its later amendments or comparable ethical standards.

\section{REFERENCES}

1. Le, T., Bhushan, V., Vasan, N. (2010). First Aid for the USMLE Step 1: 2010 (20th ed.). McGrawHill. p. 127. ISBN 978-0-07-163340-6.

2. "Encephaloceles Information Page". (2017). NIH. National institute of Neurological Disorders and Stroke. Retrieved September 15.

3. Broekman, Marike; Hoving, E. (2008). ""Nasal encephalocele in a child with BeckwithWiedemann syndrome"". Journal of Neurosurgery, 6(1): 485-7. doi:10.3171/PED/2008/1/6/485 Retrieved 2020-11-19.

4. Lozano, R. (2010). "Global and regional mortality from 235 causes of death for 20 age groups in 1990 and 2010: a systematic analysis for the Global Burden of Disease Study 2010". Lancet. 380 (9859): 2095-128. Doi: 10.1016/S01406736(12)61728-0. hdl:10536/DRO/DU:30050819. PMID 23245604. S2CID 1541253.

5. Greene, N.D., Copp, A.J. (2009). Development of the vertebrate central nervous system: Formation of the neural tube. Prenat Diagn, 29:303-11. doi: 10.1002/pd.2206.

6. Verma, I.C., Mathews, A.R. (1983). Congenital malformations in India. In: Satyavati GV, editor. Peoples of India: Some Genetical Aspects. New Delhi: Indian Council of Medical Research, 70.

7. Kulkarni, M.L., Mathew, M.A., Ramachandran, B. (1987). High incidence of neural-tube defects in South India. Lancet, 1; 1260. Lancet ;doi: 10.1016/s0140-6736(87)92705-X

8. Sharma, J.B., Gulati, N. (1992). Potential relationship between dengue fever and neural tube defects in a northern district of India. Int $\mathbf{J}$ Gynaecol Obstet, 39; 291-5. doi: 10.1016/00207292(92)90260-p

9. Frey, Lauren; Hauser, W. Allen. (2003). "Epidemiology of Neural Tube Defects". Epilepsia. 44(s3): 4-13. doi:10.1046/j.1528-1157.44.s3.2.x. ISSN 1528-1167. PMID 12790881.

10. Ordonez, E., Davis, M.C. (2018). Reducing inequities in preventable neural tube defects: the critical and underutilized role of neurosurgical advocacy for folate fortification, Journal of Neuro surgery 45;https://doi.org/10.3171/2018.7.FOCUS18231

11. Practice Bulletin No. 187: Neural Tube Defects, Obstetrics \& Gynecology: December 2017 Volume 130 - Issue 6 - p e279-e290 doi: 10.1097/AOG.0000000000002412;

12. Greene, N.D., Copp, A.J. (2014). Neural tube defects. Annu Rev Neurosci, 37; 221-42. DOI: 10.1146/annurev-neuro-062012-170354

13. Lew, S.M., Kothbauer, K.F. (2007). Tethered cord syndrome: an updated review. Pediatr Neurosurg, 43(3); 236-48. doi: 10.1159/000098836

14. Piro, E., Schierz, I. A. M., Giuffrè, M., Cuffaro, G., La Placa, S., Antona, V., ... \& Corsello, G. (2018). Etiological heterogeneity and clinical variability in 
Karkera Shilpa; Sch Int J Anat Physiol, Jan., 2022; 5(1): 9-14

newborns with esophageal atresia. Italian journal of pediatrics, 44(1), 1-6.

15. Castillo, J., Gandy, K., Bradko, V., \& Castillo, H. (2019). Language and Latino immigrants living with spina bifida: Social determinants of health-the missing dimension in quality of life research. Journal of pediatric rehabilitation medicine, 12(4), 345-359.

16. Hamamy, H. (2014). Epidemiological profile of neural tube defects in Arab countries. Middle East Journal of Medical Genetics, 3(1), 1-10.

17. Salih, M. A., Murshid, W. R., \& Seidahmed, M. Z. (2014). Classification, clinical features, and genetics of neural tube defects. Saudi medical journal, 35(Suppl 1), S5.

18. Williams, J., Mai, C. T., Mulinare, J., Isenburg, J., Flood, T. J., Ethen, M., ... \& Kirby, R. S. (2015). Updated estimates of neural tube defects prevented by mandatory folic acid fortification-United States, 1995-2011. MMWR. Morbidity and mortality weekly report, 64(1), 1.

19. De-Regil, L. M., Peña-Rosas, J. P., FernándezGaxiola, A. C., \& Rayco-Solon, P. (2015). Effects and safety of periconceptional oral folate supplementation for preventing birth defects. Cochrane database of systematic reviews, (12).

20. Arth, A., Kancherla, V., Pachón, H., Zimmerman, S., Johnson, Q., \& Oakley Jr, G. P. (2016). A 2015 global update on folic acid-preventable spina bifida and anencephaly. Birth Defects Research Part A: Clinical and Molecular Teratology, 106(7), 520529.

21. Tadesse, A. W., Kassa, A. M., \& Aychiluhm, S. B. (2020). Determinants of neural tube Defects among newborns in AMHARA Region, ETHIOPIA: A case-control study. International Journal of Pediatrics, 2020.

22. Kadian, Y., Malik, R., Duhan, N., \& Rattan, K. (2017). Neural tube defects and maternal characteristics in a North Indian Province. African Journal of Medical and Health Sciences, 16(1), 2525.

23. Zash, R., Holmes, L., Diseko, M., Jacobson, D. L., Brummel, S., Mayondi, G., ... \& Shapiro, R. L. (2019). Neural-tube defects and antiretroviral treatment regimens in Botswana. New England Journal of Medicine, 381(9), 827-840. 